\title{
Study of Stress Partitioning in a 0.68 wt\%C Pearlitic Steel Using High Energy X-Ray Synchrotron Radiation
}

BRAHAM Chedly ${ }^{1, a^{*}}$, BACZMAŃSKI Andrzej ${ }^{2, b}$, GONZALEZ Gonzalo ${ }^{3, c}$, SIDHOM Habib ${ }^{4, d}$, GADALIŃSKA Elżbieta ${ }^{5, \mathrm{e}}$, WROŃSKI Sebastian ${ }^{2, f}$, BUSLAPS Thomas ${ }^{6,9}$,WAWSZCZAK Roman ${ }^{2, h}$

${ }^{1}$ Laboratoire Procédés et Ingénierie en Mécanique et Matériaux (PIMM, CNRS UMR 8006) Arts et Métiers-ParisTech, 151 Bd de l'Hôpital, 75013 Paris, France

${ }^{2} \mathrm{AGH}-$ University of Science and Technology, Faculty of Physics and Applied Computer Science, Al. Mickiewicza 30, 30-059 Kraków, Poland.

${ }^{3}$ Instituto de Investigaciones en Materiales, Universidad Nacional Autónoma de México Circuito exterior S/N, Cd. Universitaria, A.P. 70-360, Coyoacán, C.P. 04510, Mexico

${ }^{4}$ Mechanical, Materials and Processes Laboratory (LR99ES05), ENSIT

5, Avenue Taha Hussein 1008, University of Tunis, Tunisia

${ }^{5}$ Institute of Aviation, Materials and Structures Research Center, al. Krakowska 110/114, 02-256 Warszawa, Poland

\author{
${ }^{6}$ ESRF, 6, rue J. Horowitz, 38500 Grenoble Cedex, France

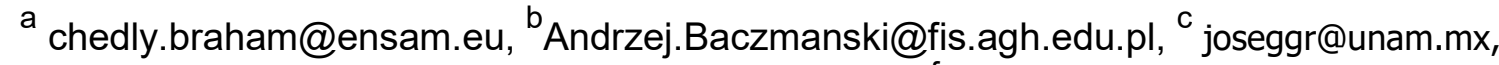 \\ d habib.sidhom@gmail.com, ${ }^{e}$ Ela.gadalinska@gmail.com, ${ }^{f}$ Sebastian.Wronski@fis.agh.edu.pl, \\ g buslaps@esrf.fr, homan.Wawszczak@fis.agh.edu.pl
}

Keywords: Pearlitic Steel, Residual Stress, X-Ray Diffraction, Synchrotron, ElastoPlasticity, Self-Consistent Model

\begin{abstract}
In the present work, the evolution of the phase stresses in a $0.68 \mathrm{wt} \% \mathrm{C}$ pearlitic steel is analyzed by synchrotron diffraction during uniaxial tensile loading, at room temperature. The diffraction measurements were done at ESRF beamline ID15B (Grenoble, France). The microstructure of the studied material, obtained after an austenitizing at $1050^{\circ} \mathrm{C}$ for 7 minutes followed by cooling under blowing air, corresponds to fully pearlitic steel with a cementite volume fraction of about $12.5 \%$. As expected, the results show a clear effect of elastic and plastic anisotropy in the both phases. For the interpretation of the diffraction data, different models are compared. In elastic range and for small plastic deformation, the self-consistent model presents the best agreement with the experimental data. For large plastic deformation, this model does not predict correctly the stress partitioning between the phases as well as the macro behavior of the studied steel. Therefore a mixture model "(1-x)*self-consistent model $+x^{*}$ Taylor" was used to take into account the interaction between the phases.
\end{abstract}

\section{Introduction}

Offering an excellent combination of ductility, strength and cost, the fully pearlitic steels are the most used plain carbon steels in manufacturing to produce wires for reinforcing tires, cables for suspension bridges, engineering springs for automotive and railroads. The role of the microstructure and specially the interlamellar space in the mechanical behavior and fatigue resistance of pearlitic steels has been studied in previous works [1,2]. In-situ diffraction technique during mechanical loading is a powerful method to investigate the mechanical behavior of the phases and the stress partitioning between the cementite and the ferrite [2-5]. Only few results concerning the role of the 
lamellar cementite in the hardening of the fully pearlitic steel have been reported [1,2]. We propose in this study to apply to fully pearlitic steel an approach based on the analysis of the mechanical properties of the polycrystalline material at the grain and phase scale using synchrotron X-ray diffraction technique and elasto-plastic models.

\section{Material}

The pearlitic steel EN C70 (SAE 1070) investigated in this study was produced by ASCOMETAL France Company in the form of bars of $80 \mathrm{~mm}$ in diameter. Its chemical composition is given in Table 1. The bars were submitted to an austenitizing at $1050^{\circ} \mathrm{C}$ for 7 minutes followed by cooling under air blown. The resulting microstructure consists of entirely pearlite colonies having an average size of 7- $8 \mu \mathrm{m}$ with cementite plates lamellae spaced by $170 \mathrm{~nm}$ (Fig. 1). The cementite fraction was estimated at 12.5 vol \% using Rietveld phase quantification from X-ray diffraction data. The mechanical properties of the obtained microstructure are reported in Table 2.

Table 1- Chemical composition of EN C70 pearlitic steel (wt\%)

\begin{tabular}{|c|c|c|c|c|c|c|c|c|c|c|}
\hline $\mathrm{C}$ & $\mathrm{Si}$ & $\mathrm{Mn}$ & $\mathrm{S}$ & $\mathrm{P}$ & $\mathrm{Ni}$ & $\mathrm{Cr}$ & $\mathrm{Mo}$ & $\mathrm{Cu}$ & $\mathrm{Al}$ & $\mathrm{Fe}$ \\
\hline 0.68 & 0.192 & 0.846 & 0.010 & 0.010 & 0.114 & 0.160 & 0.027 & 0.205 & 0.042 & balance \\
\hline
\end{tabular}

Table 2- Mechanical properties of the annealed EN C70 pearlitic steel

\begin{tabular}{|c|c|c|c|}
\hline $\begin{array}{c}\text { Yield Stress } \\
{[\mathrm{MPa}]}\end{array}$ & $\begin{array}{c}\text { Ultimate Stress } \\
{[\mathrm{MPa}]}\end{array}$ & $\begin{array}{c}\text { Elongation } \\
{[\%]}\end{array}$ & $\begin{array}{c}\text { Hardness } \\
{\left[\mathrm{HV}_{50}\right]}\end{array}$ \\
\hline 498 & 997 & 15 & $270 \pm 15$ \\
\hline
\end{tabular}

\section{Experimental setup}

X-ray diffraction measurements in a transmission mode were carried out during in situ tensile test on the studied steel at the European Synchrotron radiation Facility (ESRF, ID15B beamline). Monochromatic high energy X-ray synchrotron radiation $(\sim 90 \mathrm{keV}, \lambda=0.14256 \AA)$ with a beam size of $100 \mu \mathrm{m} \times 100 \mu \mathrm{m}$ was used for measurements of lattice strain evolution in both phases (ferrite and cementite) independently during increasing of macroscopic applied tensile stress.

Measurements were performed for numerous ferrite and cementite reflections in order to study the anisotropic effects on the loading transfer. Two dimensional diffraction patterns, measured in the range $2 \theta=1.9^{\circ}-15.5^{\circ}$, were recorded by the Thales PIXIUM 4700 detector and integrated using the FIT2D software [6] and converted in d-spacing. Then, a pseudo-Voigt function was fitted to the measured diffraction profiles and the peak positions were determined using the MULTIFIT software [7].

\section{Results and discussion}

Lattice strain evolution under tensile loading. The elastic lattice strains in the axial loading direction $\left(\varepsilon_{11}^{e}\right)$ and also in the transverse loading direction $\left(\varepsilon_{22}^{e}\right)$ were determined in both phases, for various reflections (Fig. 2). In the range of elastic deformation, the plots of phase lattice strains vs macroscopic applied stress $\left(\Sigma_{11}\right)$ show similar values of lattice strains for both phases of the studied steel $\left(\Sigma_{11} \leq 500 \mathrm{MPa}\right)$. The slopes were quite similar but the responses of phases, under loading, depend on the (hkl) planes (Fig. 2). Under larger imposed strain corresponding to macroscopic stress level higher than $500 \mathrm{MPa}$, the lattice strains of ferrite are approximately constant, while those of cementite increase significantly with the increasing applied tensile stress (Figure 2). This indicates 
clearly the occurring of load transfer from ferrite to cementite in plastic range which continues until fracture. A low hardening of ferritic phase during plastic deformation leads to slight strengthening of this phase. The different responses of lattice reflections indicate that anisotropy is also present in plastic range for both phases.

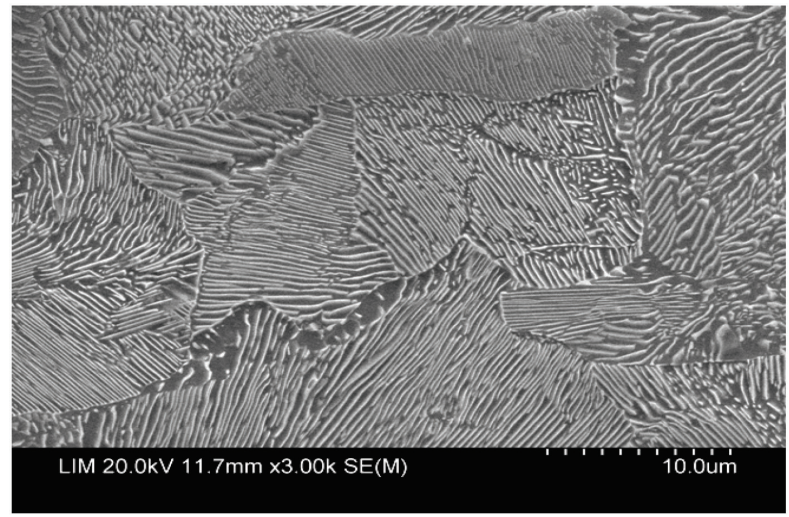

Figure 1- Microstructure of the EN C70 pearlitic steel

Elastoplastic behavior modeling. To interpret the experimental results related to the individual behavior of phases and macroscopic tensile curves, different elasto-plastic models were used and compared: Reuss, Voigt, and self-consistent model. For the self-consistent model, calculations were carried out for 10,000 inclusions representing the grains of ferrite and cementite. It was assumed that ferritic crystallites are deformed plastically due to slips on the $<111>\{211\}$ and $<111>\{110\}$ systems, while the cementite grains are deformed only elastically. The formulation of the selfconsistent elastoplastic model proposed by Berveiller and Zaoui [8] and developed by Lipinski and Berveiller [9] was used in our calculations. In this model the interaction of ellipsoidal inclusion with the homogenous medium is described by the Eshelby-type tensor.

For the ferrite phase in the elastic range of deformation, the comparison between calculations with the three chosen models and our experimental results shows a good agreement only in the case of the self-consistent model. The Voigt model assumes homogeneous deformations does not consider the elastic anisotropy and do not agree with the experimental results. In the case of the Reuss model (assuming homogeneous stresses) the effect of anisotropy was overestimated. For the cementite, also the self-consistent model gives the best range agreement but significant differences are observed in the slopes of the curves for different hkl reflections. The calculations for ferritic phase were performed using elastic constants given in Table 4. However in the case of cementite the best agreement between experimental and theoretical values was obtained when $80 \%$ of $a b$ initio values shown in Table 4 were used in modeling. Two different assumptions concerning macroscopic polycrystalline aggregate were considered: one phase and two phase materials. The comparison between these assumptions did not show any difference due to the similar elastic behavior of the ferrite and the cementite.

Until a small range of plasticity, up to $700 \mathrm{MPa}$, the classical self-consistent model is still valid and a good agreement between experimental and calculated results are obtained using $80 \%$ of $a b$ initio elastic constants for the cementite [10] (Fig. 3).

For large plastic deformation, the self-consistent model does not predict correctly the stress partitioning between the phases as well as the macro behavior of the studied steel (Fig. 4a). Therefore a mixture model is proposed in this study to better take into account the interaction between the phases (Fig. 4b). In this model the strain rate concentration tensor $A_{i j k l}$ relating macrostrain rate $\dot{E}_{k l}$ with strain rate at the polycrystalline grain $\dot{\varepsilon}_{i j}$ :

$$
\dot{\varepsilon}_{i j}=A_{i j k l} \dot{E}_{k l} \quad \text { and } \quad A_{i j k l}=(1-x) A_{i j k l}^{S C}+x I_{i j k l}
$$


where $A_{i j k l}^{S c}$ is the concentration tensor calculated using self consistent method, $I_{i j k l}$ is the unit forth range tensor representing Taylor model in which the strain is homogenous, while $x$ represent fraction of the Taylor model used in the calculations. The variable Taylor fraction $\mathrm{x} \%$ in this model is adjusted to account for the different phenomena occurring during the tensile test: the strong phase interaction (i.e. $\mathrm{x}=0.2$ ) appeared from the beginning of the ferrite plastic deformation followed by a softening stage (decreasing $\mathrm{x}$-value) for very high range of plastic deformation. The strong interaction can be attributed to the localization of dislocations around the cementite particles and dislocation pile up phenomenon. The decrease of this interaction in the followed stage may be attributed to the rearrangement of dislocations and the fragmentation of cementite when the cracking is initiated. This mixture model was tested successfully for a large plastic range as shown in Fig. $4 \mathrm{~b}$ and 5. A good agreement was found between experimental results and the mixed model calculations as well for the macroscopic behavior of the pearlitic steel (Fig. 5b) as for the evolution of lattice strains vs applied macro stress $\Sigma_{11}$, for the different reflections of the ferrite (Fig.5a) and cementite (Fig.5b).

Table 3- Single crystal elastic constants of ferrite used in modeling

\begin{tabular}{|l|l|l|l|}
\hline & C11 & C44 & C12 \\
\hline$[\mathrm{GPa}]$ & 231 & 116 & 134 \\
\hline
\end{tabular}

Table 4- Cementite ab initio elastic constants [10]

\begin{tabular}{|l|l|l|l|l|l|l|l|l|l|}
\hline & C11 & C22 & C33 & C44 & C55 & C66 & C12 & C13 & C23 \\
\hline$[\mathrm{GPa}]$ & 385 & 341 & 316 & 13 & 131 & 131 & 157 & 162 & 167 \\
\hline
\end{tabular}

\section{Conclusion}

Synchrotron X-ray diffraction measurements were applied to study the evolution of lattice strains in both phases (ferrite and cementite) of EN C70 pearlitic steel containing 12.5 (vol\%) of cementite lamellae under tensile loading. Diffraction was performed for numerous reflections, in order to evaluate the effect of microstructural anisotropy, as well as the load partitioning between ferrite and cementite during tensile test. It has been demonstrated that in elastic range cementite and ferrite are loaded similarly and there is no load transfer due to their nearly equivalent Young modulus. However at the plastic range, load is transferred gradually from ferrite to cementite. The effect of elastic/plastic anisotropic occurs in different deformation ranges.

To reproduce the experimental results related to the individual behavior of phases and macroscopic tensile curves, different elasto-plastic models were used and compared. The classical self-consistent model presented a good agreement for elasticity and small plasticity. A mixture model “ $(1-\mathrm{x}) *$ self-consistent model $+\mathrm{x}$ *Taylor" was tested successfully for a larger plastic range.

\section{Acknowledgement}

The work was supported partly by NCN - Polish National Center for Science, grants: No. UMO 2011/03/N/ST8/04058 and DEC - 2013/11/B/ST3/03787; and partly by the MNiSW - Polish Ministry of Science and Higher Education. We also acknowledge the ESRF for the use of the synchrotron radiation facilities. 

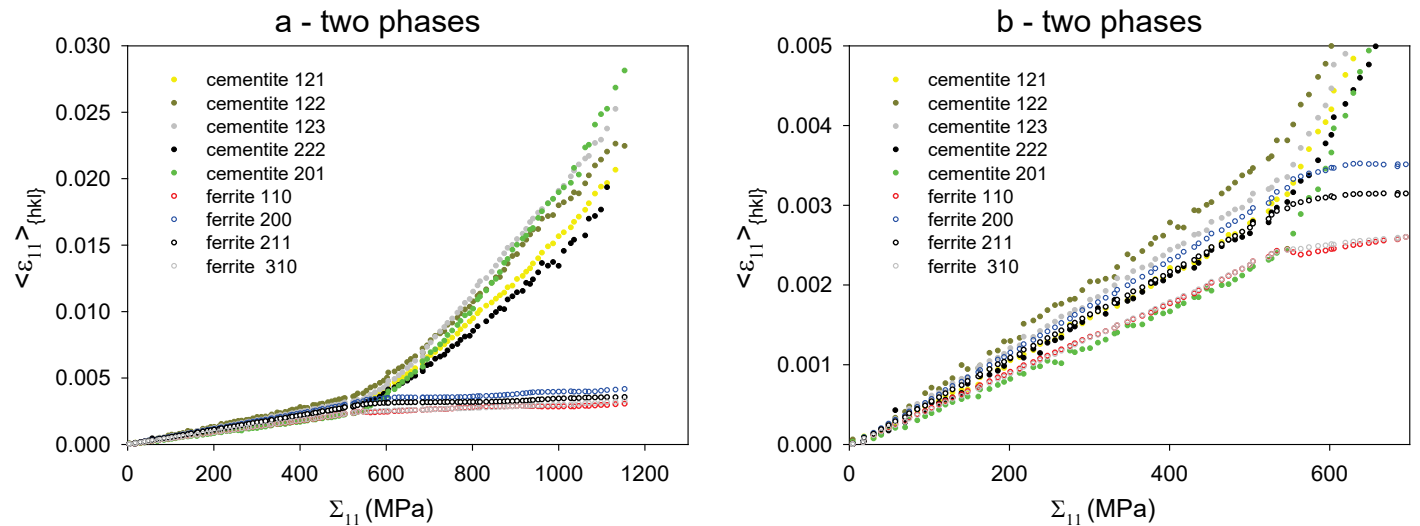

Figure 2-Variation of the lattice strains measured by synchrotron X-ray diffraction $v$ s the applied macro stress $\Sigma_{11}$, shown for large (a) and small (b) stresses applied to the sample.
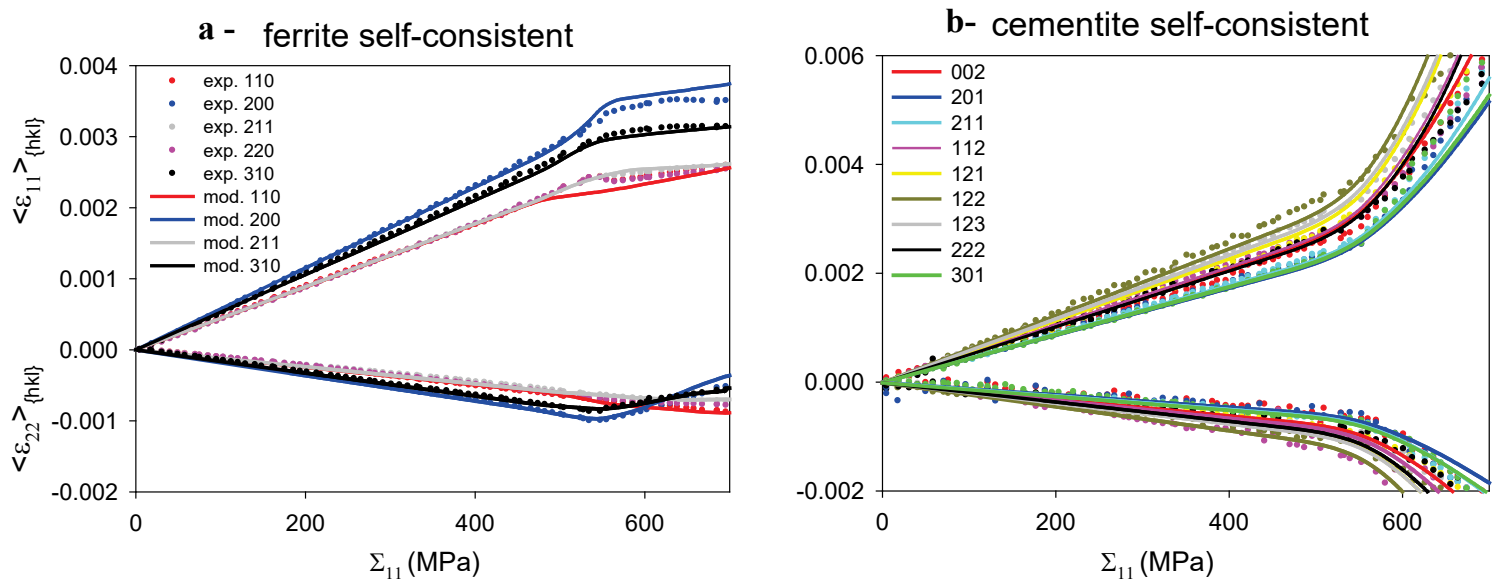

Figure 3- Longitudinal $<\varepsilon_{11}>$ and transversal $<\varepsilon_{22}>$ lattice strains vs applied macro stress $\Sigma_{11}$, comparison between experimental results and self-consistent model calculations for the ferrite (a) and the cementite (b). In the case of cementite we used $80 \%$ of ab initio elastic constants.

a - self-consistent

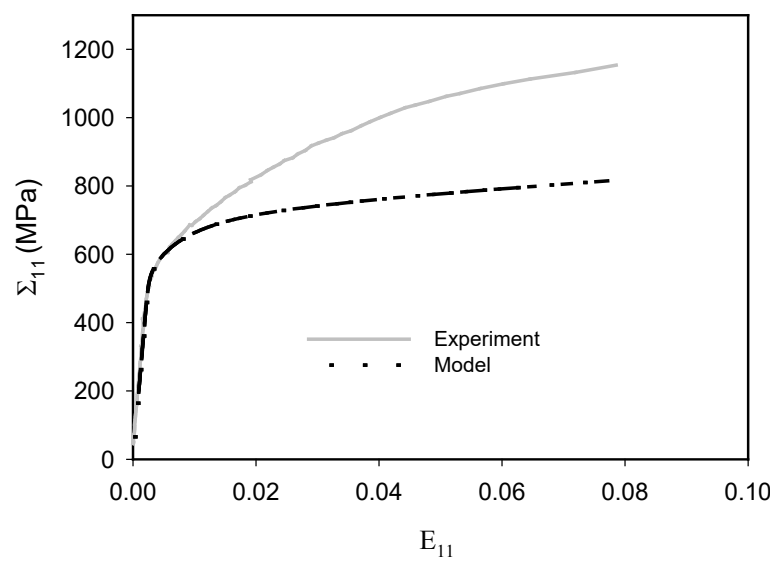

b - mixture model

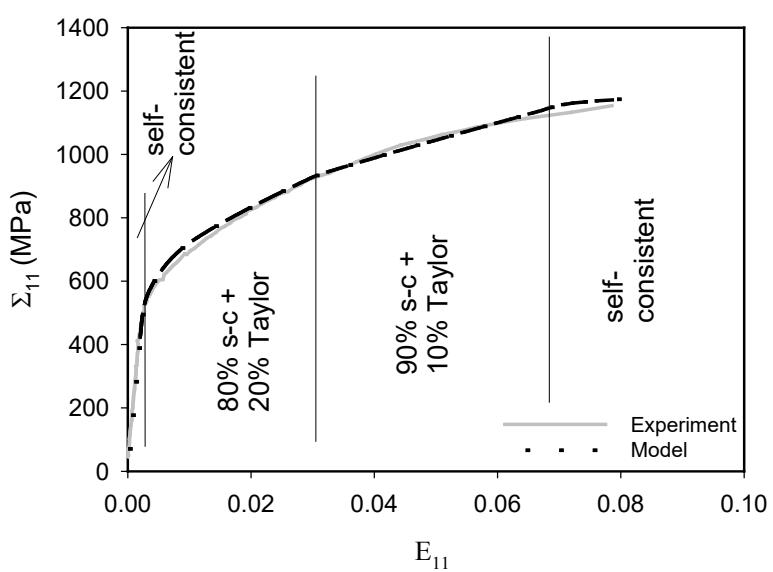

Figure 4-Macroscopic behavior of the pearlitic stee - comparıson of ine experımenıa ıensuse curve with the curves calculated by (a) the self-consistent model and (b) the mixed model " (1$x)^{*}$ self-consistent $+x *$ Taylor). 



Figure 5-Longitudinal $<\varepsilon_{11}>$ lattice strains vs macro applied stress $\Sigma_{11}$-comparison between experimental results and mixed model calculations for the ferrite (a) and the cementite (b).

\section{References}

[1] H. Sidhom, H. Yahyaoui, C. Braham, G. Gonzalez, J.Mater. Eng. Perform 2015, 24: 2586-2596. http://dx.doi.org/10.1007/s11665-015-1537-7

[2] H. Yahyaoui , H. Sidhom , C. Braham , A. Baczmanski , Materials \& Design 2014, 55 : 888897. http://dx.doi.org/10.1016/j.matdes.2013.10.062

[3] M.R. Daymond, H.G. Priesmeyer, Acta Mater 2002, 50:1613-26. http://dx.doi.org/10.1016/S1359-6454(02)00026-5

[4] V. Taupin, R. Pesci, S. Berbenni, S. Berveiller, R. Ouahab, O. Bouaziz, Mater Sci Eng 2013, A561:67-77. http://dx.doi.org/10.1016/j.msea.2012.10.086

[5] M. Nikolussi, S.L. Shang, T. Gressmann, A. Leineweber, E.J. Mittemeijer, Y.Wangb and Z.K. Liub, Scripta Materialia 2008, 59: 814-817. http://dx.doi.org/10.1016/j.scriptamat.2008.06.015

[6] A.P. Hammersley, S.O. Svensson, M. Hanfland, A.N. Fitch and D. Häusermann, High Pressure Research, 14 (1996), 235-248, http://dx.doi.org/10.1080/08957959608201408

[7] S. Merkel, Multifit/ Polydefix Polycrystal Deformation using X-rays, https://code.google.com/p/multifit-polydefix/

[8] P. Lipinski and M. Berveiller, Int. J. of Plasticity, 5, 149 (1989). http://dx.doi.org/10.1016/07496419(89)90027-2

[9] M. Berveiller, A. Zaoui, J. Mech. Phys. Solids 26, 325-344 (1978). http://dx.doi.org/10.1016/0022-5096(78)90003-0

[10] M. Nikolussi et all. Scripta Materialia 59 (2008) 814-817 